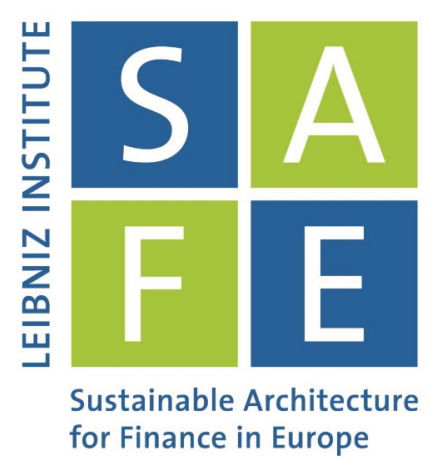

Besart Avdiu | Alfons J. Weichenrieder

\title{
Financing Costs and the Efficiency of Public-Private Partnerships
}

SAFE Working Paper No. 295

\section{Leibniz Institute for Financial Research SAFE}

Sustainable Architecture for Finance in Europe

info@safe-frankfurt.de | www.safe-frankfurt.de 


\title{
Financing Costs and the Efficiency of Public-Private Partnerships*
}

\author{
Besart Avdiu $^{\dagger 1}$ and Alfons J. Weichenrieder ${ }^{\ddagger 2}$ \\ ${ }^{1}$ Goethe University Frankfurt \\ ${ }^{2}$ Goethe University Frankfurt, Vienna University of Business and Economics, SAFE, Frankfurt, and CESifo
}

This Version, November 2020

\begin{abstract}
The paper compares provision of public infrastructure via public-private partnerships (PPPs) with provision under government management. Due to soft budget constraints of government management, PPPs exert more effort and therefore have a cost advantage in building infrastructure. At the same time, hard budget constraints for PPPs introduce a bankruptcy risk and bankruptcy costs. Consequently, if bankruptcy costs are high, PPPs may be less efficient than public management, although this does not result from PPPs' higher interest costs.
\end{abstract}

Keywords: Public-Private Partnerships, Infrastructure, Financing Costs, Default.

JEL Classification: H11, H54, G33.

*This paper is also part of the research program "Fiscal Institutions and Debt in Europe" of the Leibniz Institute for Financial Research (SAFE)

†avdiu@wiwi.uni-frankfurt.de

$\ddagger$ a.weichenrieder@em.uni-frankfurt.de 


\section{Introduction}

The provision of public infrastructure may be organized in various ways. A traditional pattern of provision is that the government plans and finances the initial investment and pays a private firm to build the infrastructure. Thereafter, the government may maintain and operate the infrastructure through government bureaucracy or hire a private firm for this task.

An alternative mode that has received considerable attention in recent decades is the formation of Public-Private Partnerships (PPPs). Various international institutions, such as the World Bank, the European Investment Bank and the IMF are supporting PPPs to improve public infrastructure. While there are different varieties of PPPs, for the purpose of this paper we define it to be an arrangement in which the government hires a private firm not only for building up the initial infrastructure. In addition, the private partner finances the investment and later on may even operate and maintain the infrastructure. In return for financing the infrastructure and maintaining it, the private firm collects a fee over a predefined time period. In reality, this period often spans 20 to 30 years.

There exists a considerable literature on the economic advantages and disadvantages of PPPs. Most notably, Hart (2003) shows that the desirability of PPPs may depend on a trade-off that results from different problems in contracting certain quality characteristics of the public services. One problem is that the builder of an infrastructure may secretly save costs in the building phase, which leads to higher costs in the maintenance phase. This problem tends to favor a bundling of the two phases in the hand of just one private firm as is the case for PPPs. Conversely, if the firm in the building phase may secretly engage in cost savings that later on reduce the non-contractible quality level of the public infrastructure, then disentangling the two functions may be preferable. ${ }^{1}$

In this paper, we discuss a different issue. The focus is on the differences in financing costs that may arise between traditional procurement solutions, in which the financing of the infrastructure occurs via issuance of government bonds, and PPPs, where the private partner firm issues bonds to finance the project. Generally, the interest rate that a private firm has to pay is higher than

\footnotetext{
${ }^{1}$ For subsequent papers that look into related efficiency issues, see Iossa and Martimort (2012), or Auriol and Picard (2013). The relative advantage of organizational forms for innovation enhancing is discussed in Wigger (2004). Inventions for innovation and cost saving are also discussed in Hoppe and Schmitz (2009).
} 
the interest on government debt, unless the government takes over extensive guarantees. At the same time, the government has to remunerate the private partner of the PPP for this financing cost via a higher fee in the maintenance phase of the project. Consequently, the question arises as to whether such a higher interest rate may be taken as a cost disadvantage of the PPP. In Germany, for example, several audit courts have decided that this is the case. ${ }^{2}$ This view is contested, though, ${ }^{3}$ and the present paper provides a first model-based analysis showing that the interest rate advantage of the government over private investors is generally not an argument against PPPs.

An important reason for why private contractors will pay a higher interest is the possibility that the private firm defaults and the repayment of the principal plus interest fails. In turn, this possibility will depend on how much risk arises for the private contractor.

Three risks usually apply to public infrastructure projects. First, there is a market risk. The infrastructure may have a projected demand, but ex post, the actual demand may fall short of this projected demand. This risk may be borne by the government and eventually the taxpayer. Some PPPs, however, impose some of this risk on the private contractor by making the remuneration in the operating and maintenance phase dependent on actual usage. Second, there is a risk that the true construction costs deviate from the estimates. Third, there is the availability risk during the operating phase. The infrastructure, due to unexpected maintenance or natural disasters, may be unavailable for usage. For the sake of exposition, this paper will concentrate on only one type of risk: the uncertainty of construction costs.

The existence of risks often implies that there are means and instruments to reduce these risks. Depending on economic incentives, effort may or may not be taken to deal with the risks. In the case of a private PPP contractor it may be important that some of the risks, such as the project cost risk, is indeed taken over. Only then may we expect that effective measures are taken to act in a cost-efficient way. This suggests that the cost effectiveness of a PPP depends on the risk allocation. A higher interest rate, which reflects higher risk for the contractor, may be needed in order for higher cost efficiency to materialize.

As mentioned above, an argument by audit courts against PPPs is that these have higher interest

\footnotetext{
${ }^{2}$ The Presidents of the German Audit Courts (2011) assert a financing advantage of traditional procurement.

${ }^{3}$ See Wissenschaftlicher Beirat beim Bundesfinanzministerium (2016, p. 26).
} 
costs than the government. For this reason, so the argument, they would have to provide or build public infrastructure at a lower real cost to make up for this disadvantage in financing costs. The present paper contributes to this discussion. In our analysis, the reason for the higher financing cost of PPPs is that, with some probability, investors are not paid in full. While this increases the interest rate, it also reduces the expected value of a PPPs repayment to investors. Overall, the higher interest rate is therefore not a disadvantage as the expected repayment is lowered through the possibility of default. At the same time, however, the possibility of default implies possible bankruptcy costs that are absent in the case of projects under government management, as in this case cost shocks lead to taxpayer financed bailouts.

Consequently, when determining whether and to what extent PPPs should be used, this paper holds that there is a trade-off between the lower real cost of public infrastructure that results from the harder budget constraints of PPPs and the higher bankruptcy cost that PPPs face. This consideration should be seen as a complement to existing papers and arguments, which have abstracted from financing costs and defaults.

The remainder of the paper is organized as follows. The next section sets up a soft budget constraint problem and introduces the assumptions that are necessary to assure that a PPP operates under a harder budget constraint than a project managed by the government. Section 3 will introduce the modelling of cost structures, default probabilities and will determine the interest cost that results. Section 4 contains the efficiency comparison of PPPs and traditional government financing. Section 5 provides a summary and an outlook for future research and open questions.

\section{The Soft Budget Constraint Problem}

We begin by analyzing the cost efficiency of building public infrastructure. The analysis here borrows from the standard literature on soft budget constraints (as summarized in Sheshinski and Lopez-Calva, 2003). The model is represented by the game tree in Figure ?? and the equilibrium concept used is a subgame perfect Nash equilibrium. There are two players, the manager of the public project and the government. The first payoff in the game tree corresponds to the manager's 
payoff, while the second is the government's payoff. Later on, we will also introduce the firm for which the manager decides and the investors who help to finance the private firm's cost, but as these do not act strategically, they are left out of the game here.

A manager of a project (whether employed by the government or a private firm) can choose to either exert high effort, denoted $i_{H}$ or low effort $i_{L}$. Throughout the paper, superscripts $j \in\{G, P\}$ will be used to denote the type of project management. In case the project is financed and managed by the government, we have the superscript $G$. In the case of a PPP we use the superscript $P$. Subscripts $k \in\{H, L\}$ will be used to denote the high and low effort cases, respectively.

For simplicity, we normalize the cost of low effort to zero and denote the cost of high effort by $i>0$. The effort costs are assumed to be sufficiently low, such that exerting effort is economically efficient. Effort is unobservable. There is a threat that a cost overrun occurs, in which case the infrastructure provider's costs exceed revenues from the project. The probability of a cost overrun is denoted $\gamma$ and will depend on a number of things, as will be discussed in Section ??.

If the manager chooses the high effort, there is a lower probability that he will land in the bad state where there is insolvency, i.e. $\gamma_{H}^{j}=\gamma^{j}\left(i_{H}\right)<\gamma^{j}\left(i_{L}\right)=\gamma_{L}^{j}$. In that case, the government can decide whether to bail out the firm or allow it to go bankrupt. We assume the government cannot default. In any event, the manager gets paid a fixed sum denoted $D^{j}$, which is determined in advance, but suffers a reputation loss of $B$ in case his firm must default. $B$ may also capture the utility loss from losing the job due to a default. It is of course an exaggeration to assume that contracts determining $D^{j}$ cannot be used to increase the efficiency of the effort decision. Yet it is well known that contracts cannot solve all problems, especially if effort is unobservable. Furthermore, pay for performance schemes may be limited. Hence, in this paper we emphasize hard budget constraints as an important factor to induce high effort.

There are no quality differences in the different provisions and hence the government's benefit from a completed project is the same, regardless of who the manager is. If the project is successful, the government receives a reward $T$. Furthermore, the government agrees to pay out an amount $\pi_{k}^{j}$ to the firm, which covers expected costs and satisfies a binding participation constraint. Higher effort lowers the expected costs and therefore reduces the payment $\pi^{j}$. 
There are two periods in the model. In the first period, the government accepts the lowest bid $\pi$, the manager decides how much effort to exert and a loan is taken at the gross interest rate $R^{j} .{ }^{4}$ All other events occur in the second period. During this period the payoffs and actual costs are realized and if the bad state is realized, either a bankruptcy or a bailout occurs. Our analysis and welfare implications are from the perspective of period 2.

In the case of a default, the project is interrupted, which is costly, and then completed. If there is a bailout the government bears a cost $S^{j}$ and in the case of a default a cost $Y^{j}$, depending on the form of management. Hence, $Y^{j}$ represents bankruptcy costs. These terms can represent costs from different delays with the project in each case, as well as political costs and public outrage. If there is a bailout, the same provider continues the project later on. In the case of default a new provider must be found. The costs $S^{j}$ and $Y^{j}$ are exogenous.

We assume that the government has an incentive to bail out the publicly managed firm, but not the PPP. This is the difference between the two cases that we aim to highlight in this paper. If PPPs also expect to be bailed out, their behavior as well as their interest rates would be the same as for the government. To ensure that the government bails out the publicly managed firm, but not the PPP, we make the following assumptions:

Assumption 1. The government chooses to bail out the publicly managed firm: $S^{G}<Y^{G}$.

Assumption 2. The government chooses not to bail out the PPP: $S^{P}>Y^{P}$.

These assumptions are natural to model a possible trade-off between PPPs and public management. We can interpret these assumptions as meaning that the government has stronger incentives to bail out firms under its own management. Such considerations are at the heart of the soft budget constraint problem in the literature.

We assume that bankruptcy is at least as costly for a PPP as for a publicly managed firm. This reflects the fact that the transaction costs may be higher in the legal process between the government and a private firm, which ensues after bankruptcy. In the process between the government and a publicly managed firm, we assume weakly lower costs, as such a process may profit from hierarchical governance that may avoid legal procedures. This is introduced by

\footnotetext{
${ }^{4}$ We abstract from bidder rents.
} 


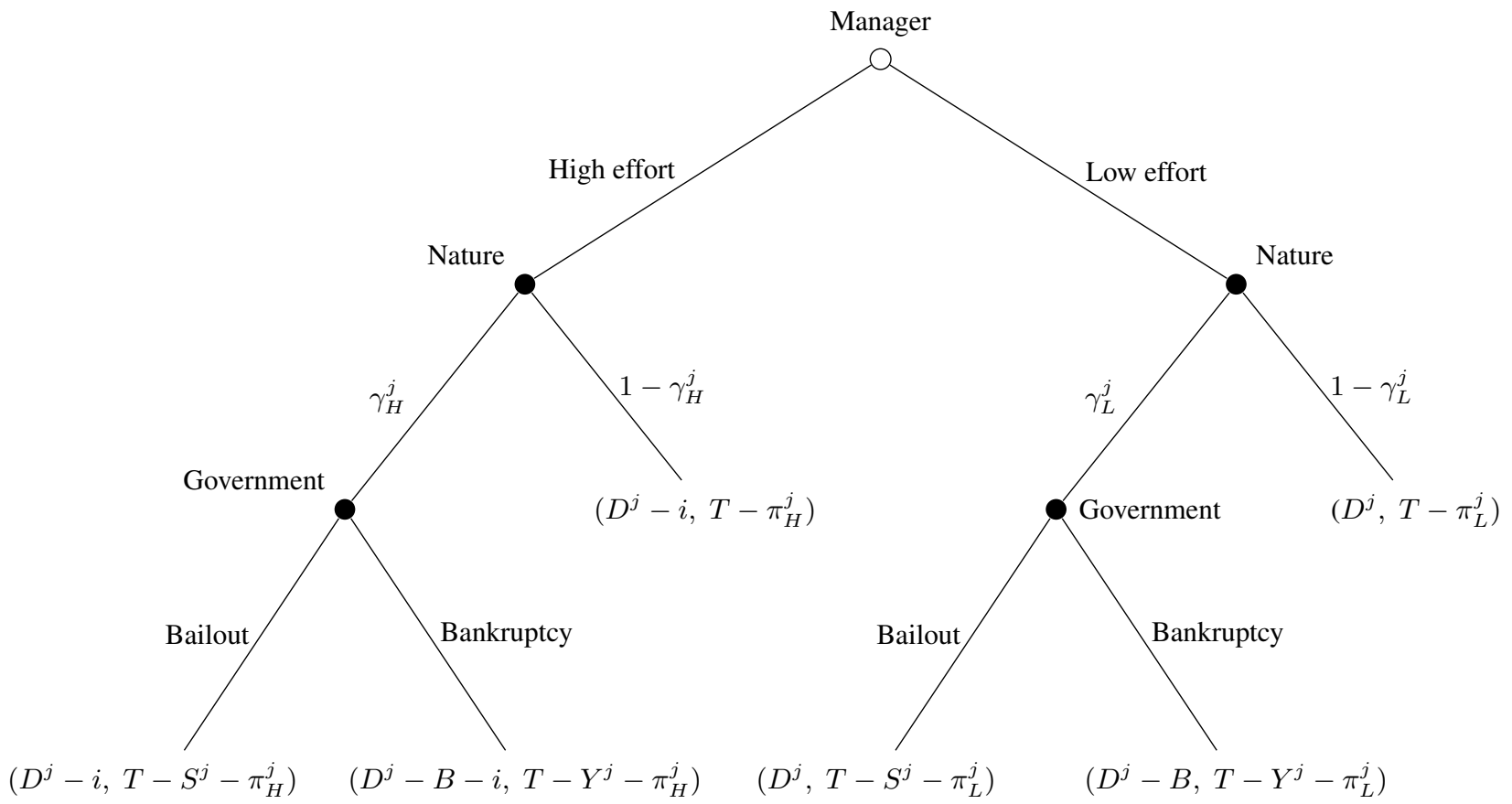

Figure 1: Soft Budget Constraint Problem

Assumption 3. A PPP bankruptcy is at least as costly for the government as the bankruptcy of a publicly managed firm: $Y^{P} \geq Y^{G}$.

From Assumptions 1 and 3, it follows that bankruptcy costs $Y^{P}$ of a PPP are larger than the costs of bailing out the publicly managed firm. Assumption 2 additionally implies that a bailout of a government firm is less costly than bailing out a PPP. This seems realistic when considering transaction costs. The government should have a stronger preference for bailing out a project it runs itself, than for bailing out a private firm, where all terms of the bailout agreement must be contracted upon in great detail. These results are stated in Lemma 1 and will be useful when evaluating the optimal form of provision.

Lemma 1. Bankruptcy costs of a PPP are larger than bail out costs of the publicly managed firm, $Y^{P}>S^{G}$. Furthermore, bailout costs of a publicly managed firm are smaller than for a PPP, $S^{G}<S^{P}$.

By introducing the assumptions above, the publicly managed firm is always bailed out, while this is never the case for the PPP. From the game tree it follows that the government manager will always choose low effort, thereby making production costlier and inefficient. The PPP, however, 
may choose the high effort, in order to avoid the reputation loss $B$ from default. The condition for the risk neutral manager of the PPP to choose the efficient action is given by the incentive constraint:

$$
i \leq\left(\gamma_{L}^{P}-\gamma_{H}^{P}\right) B
$$

In providing public infrastructure, many managerial decisions are usually necessary. For at least some of these decisions we may expect the PPP to choose the efficient action, while the government manager does not. Hence, the PPP would be more cost efficient in completing a project. For simplicity, we will restrict ourselves here to one decision with two possible choices of effort, as shown in the game tree. The expected infrastructure cost of the government is given by $E\left(C^{G}\right)=E\left(C\left(i_{L}\right)\right)$. If the PPP chooses high effort, we have $E\left(C^{P}\right)=E\left(C\left(i_{H}\right)\right)$.

The manager's wage $D^{j}$ is determined in advance by a binding participation constraint. The firms have rational expectations about the manager's effort. We normalize the manager's reservation utility to zero. Hence:

$$
\begin{aligned}
& D^{P}= \begin{cases}\gamma_{H}^{P} B+i & \text { if } i \leq\left(\gamma_{L}^{P}-\gamma_{H}^{P}\right) B \\
\gamma_{L}^{P} B & \text { else }\end{cases} \\
& D^{G}=0
\end{aligned}
$$

Note that the firm promises the payment $D^{j}$ based on expected effort choice. Because actual effort is unobservable, the incentive constraint (??) is unaffected by the participation constraint.

We denote the default probabilities by $\theta^{j}$. For the case that the government manager is always bailed out we have $\theta^{G}=0$. Furthermore, since the PPP is never bailed out, its default probability 
equals its cost overrun probability: $\theta^{P}=\gamma^{P}$. Default risk will later on play a key role in the equilibrium interest rates.

\section{Cost Overrun, Default Probabilities and Interest Rates}

In this section we examine the cost overrun probabilities, default probabilities and interest rates paid by providers of public infrastructure.

Both the firm under government management and the PPP issue bonds in the first period to finance the expected infrastructure costs $E\left(C\left(i_{k}\right)\right)$, which are immediately paid. The firm has equity $K^{j}$ and therefore borrows $E\left(C\left(i_{k}\right)\right)-K^{j}$ through bonds. To ensure that at least some borrowing occurs, we assume that expected costs are sufficiently large such that $E\left(C\left(i_{k}\right)\right)>K^{j}$. Costs are stochastic to reflect the cost overrun risk inherent in procurement problems. We have that $C\left(i_{k}\right)=\overline{C\left(i_{k}\right)}+\epsilon_{k}$, where $\overline{C\left(i_{k}\right)}$ is deterministic, $\overline{C\left(i_{L}\right)}>\overline{C\left(i_{H}\right)}$ and $\epsilon_{k}$ is a zero mean shock term. This implies that the expected costs are $E\left(C\left(i_{k}\right)\right)=\overline{C\left(i_{k}\right)}$. Here, $\epsilon^{j}$ measures the departure of realized costs from expected costs, i.e. a (possibly negative) cost overrun. Positive cost shocks can be understood for example as unexpected additional material required to rebuild faulty infrastructure that breaks down due to inefficient work in the first period. Furthermore, $\epsilon_{k}$ has a uniform distribution with zero mean and a cumulative distribution function, denoted $F_{k}$. We have $\epsilon_{k} \sim \mathcal{U}\left(-z_{k}, z_{k}\right)$, where $z_{k}$ is exogenous and $z_{L}>z_{H}$, which reflects the higher outcome uncertainty for low effort.

The bonds are bought by a risk neutral investor. For simplicity, they are zero-coupon bonds, meaning they pay no direct interest. Therefore, higher borrowing costs will be expressed through the lower price of the bond. Each bond pays out a fixed amount, which we normalize to 1.

The representative investor, who may invest in bonds or equity, maximizes a utility function of the form $U\left(c_{t}\right)=c_{t}$, which represents risk neutral preferences and solves:

$$
\max E\left(\sum_{t=1}^{2} \beta^{t} c_{t}\right) \text { s.t. } c_{t}=W_{t}+Z_{t} * x_{t}-Q_{t} x_{t+1}+K_{t}-\frac{1}{1+\rho-\psi} K_{t+1}
$$


where $t$ denotes the time period, $\beta$ is the discount factor, $K$ is the amount of capital supplied, $c$ is consumption, $W$ is some exogenous income, $Z$ is the amount the bond pays out, $Q$ is the bond price, $x$ is the number of bonds bought, $\rho$ is the required return on capital and $\psi \geq 0$ represents a possible aversion to equity, ${ }^{5}$ which may give rise to an equity premium. Note that utility maximization implies $K_{3}=0$. The first order condition with respect to the bond purchase $x_{t+1}$ is given by:

$$
Q_{t}=\beta E_{t}\left(Z_{t+1}\right)
$$

Recall that $Z=1$ in case of repayment. In case of default, the investor receives a fraction $\alpha^{j}<1$. We assume the suppliers and manager are always paid in full. Hence, the amount each of the bonds $x$ receives in case of default is $\alpha^{j}=\max \left[0, \frac{\pi^{j}-D^{j}-\epsilon^{j}}{x}\right]$. To ensure that $\alpha^{j} \geq 0$ we restrict the range of $\epsilon_{k}$ to not be too large. For later reference we define $E[\alpha \mid$ default $] \equiv \bar{\alpha}$. At the price given by equation (??), the risk neutral investor is willing to buy any number of bonds, i.e. lend any amount of money up to $W$, which is assumed sufficiently large. At other prices, the demand for bonds will be zero or infinity. Hence, the equilibrium bond price is determined by:

$$
Q_{t}=\beta\left[1-\theta^{j}\left(1-\bar{\alpha}^{j}\right)\right]
$$

The implied interest rate in this case will be:

$$
r=\frac{1-Q_{t}}{Q_{t}}=Q_{t}^{-1}-1 \Leftrightarrow R^{j}=1+r^{j}=1 / Q_{t}^{j}=\frac{1}{\beta *\left[1-\theta^{j}\left(1-\bar{\alpha}^{j}\right)\right]}, j \in\{G, P\}
$$

This implies that higher default probabilities lead to larger financing costs. Since the publicly managed firm is always bailed out, the creditors face no risk of non-repayment. Consequently, $R^{G}=\frac{1}{\beta} \leq R^{P}$.

\footnotetext{
${ }^{5}$ This can be, for example, due to lower liquidity if the firm is not listed.
} 
Comparing the first order conditions for bonds and equity gives rise to a no-arbitrage condition. It then follows that the return on equity will equal the return on debt plus the liquidity premium. Furthermore, the investor is willing to supply as much capital $K$ as requested by the firms, as is the case for the bond supply. The optimal capital demand $K^{j}$, which then determines equilibrium capital, is discussed in section ??. We have:

$$
\rho=r^{G}+\psi=\frac{1-\beta}{\beta}+\psi
$$

We now turn to determining $\gamma^{j}$, which is given by the probability that the costs exceed the amount $\pi^{j}$ the firm receives from the government for the project.

The payment $\pi_{k}^{j}$ is determined in advance by a contract between the government and the firm, which satisfies a binding participation constraint for the firm. The profits from undertaking the project must therefore recover the capital invested plus the return on equity. The private partner faces limited liability and hence makes a profit of zero in the case of default, but positive profits otherwise. The net profit from the project for the PPP is given by $\Pi^{P}=\pi^{P}-R^{P}\left[E\left(C\left(i_{H}\right)\right)-\right.$ $\left.K^{P}\right]-D^{P}-\epsilon_{H}$. Default occurs if the net profits are negative, i.e. if $\Pi^{P}<0$. From limited liability we have $E\left(\Pi^{P} \mid \Pi^{P}<0\right)=0$. The amount $\pi^{P}$ that solves the zero net profit condition is given by:

$$
E\left(\Pi^{P}\right)=E\left(\Pi^{P} \mid \Pi^{P}<0\right) \theta^{P}+E\left(\Pi^{P} \mid \Pi^{P} \geq 0\right)\left(1-\theta^{P}\right)=(1+\rho) K^{P}
$$

Solving for the truncated expectation yields:

$$
\pi^{P}=R^{P}\left[\overline{C\left(i_{k}\right)}-K^{P}\right]+D^{P}-z_{k}+a K^{P}
$$


where $a \equiv \frac{2(1+\rho)}{1-\theta^{P}}>0$. The publicly managed firm does not have limited liability as the government provides a bailout in the event of unexpectedly high costs. Furthermore, its profits in the event of unexpectedly low costs accrue to the government, which reduces the effective payment $\pi$ by the government. Hence, the $\epsilon$ terms cancel out in each case and we have:

$$
\pi^{G}=R^{G}\left[\overline{C\left(i_{L}\right)}-K^{G}\right]+(1+\rho) K^{G}=R^{G} \overline{C\left(i_{L}\right)}+\psi K^{G}
$$

Due to the equity premium, $K$ increases the payment required for public provision. Hence, efficiency requires $K^{G}=0$, which yields:

$$
\pi^{G}=R^{G} \overline{C\left(i_{L}\right)}
$$

In the second period, the point in time at which we compare alternatives, the firm receives the amount $\pi^{k}$. It must pay the manager and pay back the credit with interest, namely $R^{j} \times$ $\left[E\left(C^{j}\right)-K^{P}\right]$. Furthermore, in this period the actual costs are realized and the firm must pay the difference between the actual costs and the amount already spent in the first period for which the credit was taken: $C\left(i_{k}\right)-E\left(C\left(i_{k}\right)\right)=\epsilon_{k}$. The probability of a cost overrun is given by:

$$
\begin{gathered}
\gamma^{j}=\text { Probability }\left[\pi^{j}<R^{j}\left[E\left(C^{j}\right)-K^{j}\right]+D^{j}+\epsilon^{j}\right] \\
\gamma^{G}=1-F_{L}(0)=\frac{1}{2} \\
\gamma^{P}=1-F_{H}\left(a K^{P}-z_{k}\right)=\max \left[0,1-\sqrt{\frac{(1+\rho) K^{P}}{z_{k}}}\right]
\end{gathered}
$$

Note that the solution for $\gamma^{P}$ involves solving a quadratic equation. Nevertheless, only the solution above implies a probability between 0 and 1 . Finally, the respective probabilities of default 
are given by:

$$
\begin{gathered}
\theta^{G}=0 \\
\theta^{P}=\gamma^{P}
\end{gathered}
$$

Inequality (??) can only hold if $\gamma_{L}^{P} \geq \gamma_{H}^{P}$, which follows directly from $z_{L}>z_{H}$, since capital is determined in advance and not made dependent on effort, because it is unobservable.

Having solved for the default probabilities, it is now possible to solve for $\bar{\alpha}, R^{P}$ and $\pi^{P}$ explicitly. This yields:

$\bar{\alpha}=\frac{\pi^{P}+K^{P}-E\left[\epsilon_{k} \mid \epsilon_{k}>\pi^{P}-R^{P}\left[\overline{C\left(i_{k}\right)}-K^{P}\right]-D^{P}\right.}{R^{P}\left[\overline{C\left(i_{k}\right)}-K^{P}\right]}=\frac{\pi^{P}-z_{k}-D^{P}+R^{P}\left[\overline{C\left(i_{k}\right)}-K^{P}\right]}{2 R^{P}\left[\overline{C\left(i_{k}\right)}-K^{P}\right]}$

$$
R^{P}=\frac{2\left[\overline{C\left(i_{k}\right)}-K^{P}\right]-\beta \theta^{P}\left(\pi^{P}-z_{k}-D^{P}\right)}{\beta\left(2-\theta^{P}\right)\left[\overline{C\left(i_{k}\right)}-K^{P}\right]}
$$

$$
\pi^{p}=\frac{\overline{C\left(i_{k}\right)}}{\beta}+D^{P}+K^{P} \psi=R^{G} \overline{C\left(i_{k}\right)}+D^{P}+K^{P} \psi
$$

Notice that the PPP's interest rate $R^{P}$ has disappeared from $\pi^{P}$, meaning that interest rate differences between PPPs and the government play no role. The intuition is that higher interest rates mean higher expected costs that will be shifted to investors. While the higher interest in itself calls for a higher $\pi^{P}$ to break even, the lower expected repayment to investors cancels this out. 


\subsection{Optimal Capital}

The PPP with the lowest bid, i.e. with the lowest $\pi^{P}$, obtains the contract. Hence, in order to be competitive, the PPP needs to minimize $\pi^{P}$. First, consider the economically interesting case where this is done by providing high effort.

A higher level of capital decreases $\pi^{P}$ by reducing the manager's payment $D^{P}=\gamma_{H}^{P} B+i$, as long as $\gamma_{H}^{P}>0$, but for $\psi>0$ also increases $\pi^{P}$ due to the cost of capital.

If the PPP owners find it optimal to induce high effort, then they must ensure that the incentive constraint from inequality (??) holds. A first observation is that $K^{P}=0$ cannot be optimal as here we have $\partial \pi^{p}\left(K^{P}=0\right) / \partial K^{P}=-\infty$.

$$
\min _{K^{P}} \pi^{P} \text { s.t. } \frac{i}{B} \leq \sqrt{(1+\rho) K^{P}}\left(z_{H}^{-0.5}-z_{L}^{-0.5}\right)
$$

For $\gamma_{H}^{P}>0$, the optimal $K^{P}$ is then given either by the first order condition for a minimum of $\pi^{P}$ or by the corner solution, where the incentive constraint (??) binds with equality. The second order conditions ensure a minimum for the interior solution of $K^{P}$. In the case $\gamma_{H}^{P}=0$, the optimal capital stock can be derived as $\frac{z_{H}}{1+\rho}$. A further increase in capital would be useless as it cannot further reduce $\gamma_{H}^{P}$, but would carry a capital $\operatorname{cost}^{6}$.

$$
K^{P}\left(i_{H}\right)= \begin{cases}\max \left[\frac{B^{2}(1+\rho)}{4 z_{H} \psi^{2}}, \frac{i^{2} z_{H} z_{L}}{B^{2}(1+\rho)\left(\sqrt{z_{L}}-\sqrt{z_{H}}\right)^{2}}\right] & \text { if } \gamma_{H}^{P}>0 \\ \frac{z_{H}}{1+\rho} & \text { else }\end{cases}
$$

Similarly, if low effort is optimal and $\gamma_{L}^{P}>0$, the PPP will either choose the interior solution for $K^{P}$ or the highest possible $K^{P}$ such that the incentive constraint does not hold. If $\gamma_{L}^{P}=0$,

\footnotetext{
${ }^{6}$ Note that up to $\gamma_{H}^{P}=0$, an increase in $K^{P}$ always eases the restriction (??). Hence, our solution $\frac{z_{H}}{1+\rho}$ never violates this restriction, as long as high effort can be achieved for any $K^{P}$.
} 
then there is no use in increasing $K^{P}$ further. Moreover, if $\gamma_{L}^{P}=0$, the incentive constraint never holds. Therefore:

$$
K^{P}\left(i_{L}\right)= \begin{cases}\min \left[\frac{B^{2}(1+\rho)}{4 z_{L} \psi^{2}}, \frac{i^{2} z_{H} z_{L}}{B^{2}(1+\rho)\left(\sqrt{z_{L}}-\sqrt{z_{H}}\right)^{2}}-\nu\right] & \text { if } \gamma_{L}^{P}>0 \\ \frac{z_{L}}{1+\rho} & \text { else }\end{cases}
$$

Here, $\nu$ is a positive, infinitesimally small number. The PPP will find high effort optimal if:

$$
\pi^{P}\left(i_{H}\right)-\pi^{P}\left(i_{L}\right)=\frac{\overline{C^{\left(i_{H}\right)}}-\overline{C\left(i_{L}\right)}}{\beta}-\left(\gamma_{L}^{P}-\gamma_{H}^{P}\right) B+i+\left[K^{P}\left(i_{H}\right)-K^{P}\left(i_{L}\right)\right] \psi<0
$$

It follows that $\gamma_{L}^{P} \geq \gamma_{H}^{P}$. As $\overline{C^{\left(i_{H}\right)}}<\overline{C\left(i_{L}\right)}$ and $\gamma_{L}^{P} \geq \gamma_{H}^{P}$, this condition is likely to hold for a small equity premium $\psi$.

In the next section, we will restrict our attention to the case $\gamma_{H}^{P}>0$. In the reverse case, $\gamma_{H}^{P}=0$, the firm can without cost employ as much capital that default is excluded and the interest available to the PPP is the riskless rate. Obviously, from the discussion in the introduction about the interest rate disadvantage of PPPs, this is not an interesting starting point.

\section{The Trade-Off between Construction Costs and Bankruptcy \\ Costs}

We now turn to the discussion of the trade-off between PPPs' lower construction cost in the case of high effort and their higher bankruptcy cost. We continue to abstract from quality considerations discussed in Hart (2003) and the gross benefit of society from the public infrastructure, $T$, is the same regardless of the provider. Therefore, the supplier with the smallest social cost should be chosen. The costs can be influenced by the choice of effort and bankruptcy costs. The government manager chooses a lower effort and therefore may work less efficiently than the PPP. The publicly managed firm on the other hand has the lower bankruptcy costs.

The social planner chooses the option that yields the largest expected total payoff from the 
game tree in Figure ??. Recall that the government internalizes the utility of the public infrastructure $T$, meaning they are captured in the payoffs. The social planer sums the payoffs of the government and manager. As the investor is indifferent to funding the project or not and firms satisfy a binding participation constraint, we do not consider these two players in the welfare analysis. We allow for the possibility that public funds are associated with distortionary taxation which may result in a social cost of public funds $\lambda \geq 1$. This measure scales the government's costs in the social welfare comparison. Supposing the PPP chooses high effort, it is more desirable than government provision if and only if:

$$
\begin{array}{r}
\left(1-\gamma^{P}\right)\left[D^{P}-i+T-\lambda \pi^{P}\right]+\gamma^{P}\left[D^{P}-B-i+T-\lambda\left(\pi^{P}+Y^{P}\right)\right]> \\
\left(1-\gamma^{G}\right)\left[D^{G}+T-\lambda \pi^{G}\right]+\gamma^{G}\left[D^{G}+T-\lambda\left(\pi^{G}+S^{G}\right)\right]
\end{array}
$$

Simplifying yields the condition:

$$
\frac{1}{\beta}\left(\overline{C\left(i_{H}\right)}-\overline{C\left(i_{L}\right)}\right)+K^{P} \psi+i<\gamma^{G} S^{G}-\gamma^{P} Y^{P}-\gamma^{P} B
$$

The argument for the use of PPPs often consists of the higher infrastructure cost efficiency of PPPs, which holds in our case if they choose high effort. In that case, the PPP may be optimal. However, PPPs are allowed to go bankrupt, which involves costs. If bankruptcy costs are sufficiently low, then PPPs can dominate, otherwise publicly managed firms may be preferable. Hence, the choice of PPP involves a trade-off between infrastructure cost efficiency and bankruptcy costs.

Proposition 1. If the PPP chooses high effort and the cost of capital is sufficiently high such that $\gamma_{H}^{P}>0$, then there can be a trade-off involving the infrastructure cost efficiency gains from PPPS and their higher bankruptcy costs.

Proof. Equation (??) is impossible to sign without assumptions on the average infrastructure costs and bankruptcy and bailout costs. We have $\overline{C\left(i_{H}\right)}<\overline{C\left(i_{L}\right)}$. As the difference between the average infrastructure costs increases, i.e. as $\overline{C\left(i_{H}\right)}-\overline{C\left(i_{L}\right)} \rightarrow-\infty$, PPPs will dominate. 
From Lemma ?? we know that $Y^{P}>S^{G}$. As the difference in bankruptcy costs increases, i.e. as $Y^{P}-S^{G} \rightarrow \infty$ or $B \rightarrow \infty$, public provision will dominate.

Consequently, the choice of PPP is indeterminate and involves a trade-off between cost efficiency gains and bankruptcy costs.

Even though the PPP has lower infrastructure costs, there can be a trade-off involved, which is due to different bailout and bankruptcy costs, as the previous proposition shows. These different bankruptcy and bailout costs are a central feature of the model, as they make sure that publicly managed projects are bailed out, while PPPs are not. The latter is a requirement for PPPs' higher effort and lower construction cost.

As mentioned in the introduction, a frequent argument put forward against PPPs is that they face higher interest rates than the government and are therefore less efficient. Our analysis, however, shows that such pecuniary considerations do not play a role.

Proposition 2. Interest rates are irrelevant when considering the cost efficiency of PPPs.

Proof. To evaluate the cost efficiency of PPPs we examine $\pi^{P}$. Looking at equation (??), it would indeed seem that a higher $R^{P}$ increases $\pi^{P}$. However, this is misleading. From equation (??), we see that the PPP's infrastructure costs are effectively multiplied with the government interest rate $R^{G}$. Hence, interest rate differences do not play a role.

The reason, in our set up, is that the increase in the interest rate comes from an increase in the default probability. From the perspective of the firm, the disadvantage of higher interest rates is therefore matched by the reduced expected repayment. 


\section{Conclusion}

The paper considers the welfare cost of producing public infrastructure via government management or via a PPP. A starting point of the analysis is that PPPs are often confronted with the critique that the higher interest cost of private firms implies a disadvantage compared to projects that are managed and financed by the government directly. Previous papers, such as Hart (2003), abstract from this question, as there are no financing costs or default risks in these analyses. In pursuing the question to which extent higher financing costs of PPPs imply an efficiency problem, our paper ignores quality uncertainty and the role of innovations, which have been at the focus of previous literature on PPPs.

Our framework starts from the assumption that, in the case of a cost overrun, projects under public management are bailed out. This produces soft budget constraints that explain the low cost efficiency in the building of the public infrastructure. At the same time, a failing PPP is not bailed out, which may increase efficiency via hard budget constraints. However, for this to be optimal, we derive that the bankruptcy cost of the PPP must be higher than the bailout cost of the publicly managed project. The paper shows that the decision whether to employ PPPs for public infrastructure provision involves solving a trade-off between bankruptcy and construction costs. A key factor in this trade-off is the presence of bankruptcy risk, which increases incentives to avoid a cost overrun, while also increasing expected bankruptcy costs. If bankruptcy costs are sufficiently high, the cost of producing hard budget constraints becomes too high and public management may be the better alternative. At the same time, we find that the higher interest cost of PPPs compared to government management and financing is not welfare relevant, as it just results from a smaller probability of paying the investors back. This said, the higher interest rate indicates that investors anticipate the possibility of default, which in turn brings up the issue of bankruptcy costs.

We hope that the paper provides a useful framework that may be used for future research on government policies which try to reduce the cost of capital for PPPs. In the EU, for example, the European Commission's Project Bond Initiative guarantees a risky junior tranche of PPPs bond issuances. While government intervention may be suitable to lower the interest cost of PPPs, there may be important repercussions for the incentives to act cost efficiently to the extent that the 
intervention reduces the overall default risk.

\section{References}

Auriol, E. and P.M. Picard (2013), “A Theory of BOT Concession Contracts”, Journal of Economic Behavior \& Organization 89, 187-209.

Hart, O. (2003), "Incomplete Contracts and Public Ownership: Remarks, and an Application to Public-Private Partnerships", Economic Journal 113, C69-76.

Hoppe, E.I. and P.W. Schmitz (2010), "Public versus Private Ownership: Quantity Contracts and the Allocation of Investment Tasks", Journal of Public Economics 94, 258-268.

Iossa, I. and D. Martimort (2012), "Risk Allocation and the Costs and Benefits of PublicPrivate Partnerships", Rand Journal of Economics 43, 442-474.

Presidents of the German Audit Courts (2011), Gemeinsamer Erfahrungsbericht zur Wirtschaftlichkeit von ÖPP-Projekten, Wiesbaden.

Sheshinski E. and L.F. Lopez-Calva (2003), "Privatization and its Benefits", CESifo Economic Studies 49, 429-459.

Wigger, B.U. (2004), "Public versus Private Production of Government Services", Journal of Business Economics 74, 53-67.

Wissenschaftlicher Beirat beim Bundesfinanzministerium (2016), Chancen und Risiken Öffentlich-Privater Partnerschaften, Report of the Scientific Council at the Federal Ministry of Finance, Germany, 02/2016. 


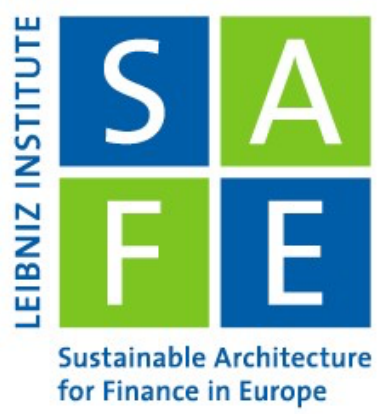

\section{Recent Issues}

No. 294 Christian Alemán, Christopher Busch, Alexander Ludwig, Raül Santaeulàlia-Llopis

No. 293 Christoph Hambel, Holger Kraft, André Meyer-Wehmann

No. 292 Andrea Modena

No. 291 Loriana Pelizzon, Satchit Sagade, Katia Vozian

No. 290 Nicola Fuchs-Schündeln, Dirk Krueger, Alexander Ludwig, Irina Popova

No. 289 Christian Schlag, Michael Semenischev, Julian Thimme

No. 288 Michele Costola, Michael Nofer, Oliver Hinz, Loriana Pelizzon

No. 287 Kevin Bauer, Nicolas Pfeuffer, Benjamin M. Abdel-Karim, Oliver Hinz, Michael Kosfeld

No. 286 Andreass Hackethal, Michael Kirchler, Christine Laudenbach, Michael Razen, Annika Weber

No. 285 Elena Carletti, Tommaso Oliviero, Marco Pagano, Loriana Pelizzon, Marti G. Subrahmanyam

No. 284 Monica Billio, Michele Costola, Iva Hristova, Carmelo Latino, Loriana Pelizzon

No. 283 Jannis Bischof, Christian Laux, Christian Leuz
Evaluating the Effectiveness of Policies Against a Pandemic

When Should Retirees Tap Their Home Equity?

Recapitalization, Bailout, and Long-run Welfare in a Dynamic Model of Banking

Resiliency: Cross-Venue Dynamics with Hawkes Processes

The Long-Term Distributional and Welfare Effects of Covid-19 School Closures

Predictability and the Cross-Section of Expected Returns: A Challenge for Asset Pricing Models

Machine Learning Sentiment Analysis, COVID-19 News and Stock Market Reactions

The Terminator of Social Welfare? The Economic Consequences of Algorithmic Discrimination

On the (Ir)Relevance of Monetary Incentives in Risk Preference Elicitation Experiments

The COVID-19 Shock and Equity Shortfall: Firm-Level Evidence from Italy

Inside the ESG Ratings: (Dis)agreement and Performance

Accounting for Financial Stability: Bank Disclosure and Loss Recognition in the Financial Crisis 